\title{
PRODUTOS POTENCIAIS À INDICAÇÃO GEOGRÁFICA NO ESTADO DO PARÁ: Estudo de caso das feiras na cidade de Belém / PA
}

\section{POTENTIAL PRODUCTS FOR GEOGRAPHICAL INDICATION IN THE STATE OF PARÁ: \\ Case study of the street markets in the city of Belém / PA}

\section{PRODUCTOS POTENCIALES A INDICACIÓN GEOGRÁFICA EN EL ESTADO DE PARÁ: Estudio de caso de las ferias en la ciudad de Belém / PA}

\section{Resumo}

O presente artigo visa discutir os produtos potenciais ao signo de Indicações Geográficas no estado do Pará. As Indicações Geográficas (IGs) são signos distintivos que contribuem para a (re) valorização dos conhecimentos tradicionais, pois o reconhecimento de uma IG possibilita a proteção de um território que se tornou conhecido por produzir um produto com características e qualidades diferenciadas. A pesquisa foi realizada por meio de levantamentos bibliográficos e documentais obtidos através de fontes oficiais ligadas ao Fórum Técnico Estadual de Indicações Geográficas e Marcas Coletivas do Estado do Pará e de campo, nas feiras livres da 25 e do Ver o peso, localizadas em Belém / PA. Os resultados da pesquisa mostraram que no estado do Pará existem muitos produtos com potencial para IG e a maioria é comercializada in natura, sendo necessário investir na sua agroindustrialização, para que haja agregação de valor ao produto, $e$ oportunizar políticas que proporcionem o desenvolvimento territorial.

Palavras-Chave: Produtos Potenciais. Território. Agroindustrialização.

\section{Abstract}

This article aims to discuss the potential products to receive the sign of Geographical Indications in the state of Pará. Geographical Indications (GIs) are distinctive signs that contribute to the (re) valorization of traditional knowledge, since the recognition of a GI makes it possible to protect a territory that has become known for producing a product with different characteristics and qualities. The research was carried out by bibliographical and documentary surveys obtained through official sources connected to the State Technical Forum of Geographical Indications and Collective Marks of the State of Para and the field, at the street markets of 25 and Ver o Peso, located in Belém / PA. The research results showed that in the state of Pará there are many products with potential for GI and the majority are commercialized in natura, being necessary to invest in its agroindustrialization, so that it adds value to the product, and to create policies that provide territorial development.

Key words: Potential Products. Territory. Agroindustrialization.

\section{Resumen}

Este artículo tiene como objetivo discutir los productos potenciales al signo de Indicaciones Geográficas en el estado de Pará. Las Indicaciones Geográficas (IGs) son signos distintivos que contribuyen para la (re)valorización de los conocimientos tradicionales, ya que el reconocimiento de una IG significa la protección de un territorio que se tornó conocido por producir un producto con características y cualidades diferenciadas. La pesquisa fue realizada por medio de investigación bibliográfica, documental, obtenida mediante fuentes oficiales vinculadas al Fórum Técnico Estadual de Indicações Geográficas e Marcas Coletivas do Estado do Pará, y de campo, a partir de un estudio de caso en las ferias libres de la 25 y Ver o

1 Graduanda do Curso de Licenciatura Plena em Geografia, da Universidade do Estado do Pará (UEPA). E-mail: stephanieolvr@hotmail.com

2 Docente do Programa de Pós-Graduação em Geografia da UEPA (PPGG). E-mail: bvalente7@uepa.br 


\section{Produtos potenciais à indicação geográfica no Estado do Pará: \\ Estudo de caso das feiras na cidade de Belém-Pa}

Peso situadas en Belém / PA. Los resultados de la investigación mostraron que en el estado de Pará existen muchos productos con potencial para IG y la mayoría es comercializado in natura, siendo necesario investir en su agro-industrialización para que haya agregación de valor al producto y dar la oportunidad a políticas que proporcionen el desarrollo territorial.

Palabras-Claves: Productos potenciales. Territorio. Agro-industrialización.

\section{INTRODUÇÃO}

A globalização promoveu mudanças em diversos setores da nossa vida, introduzindo novas tecnologias, diferentes formas de comunicação, de comercialização e de consumo. No espaço rural esse fenômeno também é perceptível, na medida em que são utilizadas e difundidas técnicas modernas direcionadas ao aumento de produtividade e produção visando atender preferencialmente os mercados (inter) nacionais. Como resultado, tem-se o surgimento de cadeias agroalimentares globais, chamadas por Ploeg (2008) de Impérios Alimentares e a homogeneização nos espaços rurais.

Embora esses processos aconteçam em escala global, existem movimentos que contrariam essa lógica de padronização e propõem a retomada e valorização dos conhecimentos tradicionais do homem do campo, seja por meio da bioprospecção ou da Indicação Geográfica (IG) (NUNES, BANDEIRA E NASCIMENTO, 2012). Segundo Saccaro Júnior (2011, p. 229), a bioprospecção consiste em um processo pelo qual, a partir do uso da biodiversidade e dos conhecimentos tradicionais, realiza-se uma "[...] busca sistemática por organismos, genes, enzimas, compostos, processos e partes provenientes de seres vivos em geral, que possam ter um potencial econômico e, eventualmente, levar ao desenvolvimento de um produto[...]", assim contribuem na produção de fármacos, cosméticos, alimentos etc. Já as IGs, são reconhecidas como signos distintivos que objetivam diferenciar os produtos e produtores dos demais, por meio da origem geográfica, tendo como parâmetro a notoriedade e/ou os fatores naturais e humanos que singularizam um produto (BRUCH et al, 2014).

Geralmente, as medidas de (re) valorização dos conhecimentos tradicionais acompanham também a valorização dos elementos simbólicos, culturais e identitários presentes no território. A participação social e governamental nesse processo é fundamental, visto que são os grandes promotores das políticas de diferenciação e articulam estrategicamente todos os elementos destes espaços objetivando o desenvolvimento territorial (DULLIUS, FROEHLICH E VENDRUSCOLO, 2008).

A temática das Indicações Geográficas se insere nas ações que envolvem a valorização e desenvolvimento dos territórios. Sua inclusão se deve aos efeitos positivos provenientes de um potencial identificável. Reconhecer um produto potencial é considerado uma das primeiras etapas do processo de diferenciação e valorização de conhecimentos de matriz territorial. Relacionado a isso, este trabalho propõe identificar e analisar os produtos potenciais ao signo de indicação geográfica no estado do Pará.

A metodologia utilizada para a elaboração do artigo consistiu em pesquisas bibliográficas em periódicos científicos, livros, dissertações e teses sobre indicação geográfica. Realizamos também pesquisas documentais e participações em eventos promovidos pelas instituições responsáveis pelo fomento das IGs no Pará, as quais nos permitiram obter informações e dados dos órgãos oficiais pertencentes ao Fórum Técnico Estadual de Indicações Geográficas e Marcas Coletivas do Estado do Pará, tais como: Empresa de Assistência 


\section{Produtos potenciais à indicação geográfica no Estado do Pará: Estudo de caso das feiras na cidade de Belém-Pa}

Técnica e Extensão Rural (EMATER), Ministério da Agricultura, Pecuária e Abastecimento (MAPA), Secretaria de Desenvolvimento Agropecuário e da Pesca (SEDAP), Secretaria de Estado de Turismo (SETUR), Serviço Brasileiro de Apoio às Micro e Pequenas Empresas (SEBRAE). Por meio da pesquisa de campo foi possível observar, registrar e identificar a comercialização dos produtos potenciais à indicação geográfica, além de aplicar formulário com questões pré-elaboradas a trinta e cinco (35) feirantes que trabalham nas feiras da 25 e no Ver o Peso em Belém do Pará, pontos tradicionais de comercialização de produtos da sociobiodiversidade da Amazônia.

O artigo está estruturado partindo de uma discussão do geral para o particular. Inicialmente esclarecemos os conceitos e definições de Indicação Geográfica, apresentando seus respectivos usos e os riscos envolvidos. Na sequência, discorreremos sobre o contexto das IGs no Brasil, apresentando o panorama geral desse signo distintivo. Por fim, abordamos de maneira específica as Indicações Geográficas no estado do Pará, enfatizando os primeiros projetos, produtos depositados no INPI e a discussão sobre os produtos potenciais encontrados nas feiras da 25 e Ver o Peso.

\section{INDICAÇÃO GEOGRÁFICAS: DEFINIÇÕES, USOS E RISCOS}

Ao introduzir-se no mundo das Indicações Geográficas (IG) é imprescindível conhecer sua origem histórica, as mudanças e as transformações pelo qual este signo distintivo vem passando no decorrer do tempo.

A compreensão das IGs surgiu a partir da percepção de produtores e consumidores a respeito de produtos com características típicas originadas de determinados locais (CERDAN et al, 2014). A prática de associar um produto a um território enfatiza a existência de um diferencial, que pode estar relacionado a elementos físicos-sensoriais ou subjetivos e que são expressos por meio de um produto ou serviço.

O exercício de associações é recorrente ao analisar a história da comercialização dos alimentos, visto que, alguns grupos utilizavam sinais distintivos para indicar a origem de um produto. Exemplos disso podem ser encontrados em passagens bíblicas, como em Cânticos ao mencionar os vinhos de En-Gedi e o cedro do Líbano $^{3}$. Na Europa, durante o período romano e grego, havia modelos de diferenciação semelhantes a estes, referindo-se ao mármore de Carrara, ao bronze de Corinto entre outros (ALMEIDA, 2010).

A necessidade de proteger a procedência dos produtos se intensificou no decorrer do tempo, principalmente quando um produto era frequentemente exportado e apresentava muita notoriedade dentro e fora do seu território. Este foi o caso do Vinho do Porto, um dos produtos de maior notoriedade da produção vinícola portuguesa. Motivados por sua notoriedade e objetivando maiores vantagens comerciais, outros vinhos começaram a utilizar a denominação "do Porto", ocasionando, assim, prejuízos econômicos aos produtores portugueses, que então solicitaram ao Primeiro-Ministro do Reino, Marquês de Pombal, que se fizesse a primeira intervenção estatal em favor da proteção do Vinho do Porto (CERDAN et al, 2014). Essas medidas foram efetivadas em 1756 com a criação da Companhia Geral da Agricultura das Vinhas do Alto Douro, uma entidade que executou a demarcação das terras juntamente com a gestão do controle da qualidade e comércio do vinho produzido na região (SOUSA, 2003).

3 BÍBLIA, Cânticos, I, 14 - III, 9. Apud CERDAN et al, 2014, p. 34 


\section{Produtos potenciais à indicação geográfica no Estado do Pará: Estudo de caso das feiras na cidade de Belém-Pa}

A adoção de medidas como esta impulsionaram a criação e evolução de outros mecanismos legais contra as falsificações e a proteção das questões relacionadas à propriedade intelectual. Entre esses podemos destacar a Convenção União de Paris (CUP) em 1883, o Acordo de Madri em 1891, o Acordo de Lisboa em 1958 e o Acordo Sobre Aspectos dos Direitos de Propriedade Intelectual Relacionados ao Comércio (TRIPS ou ADIPC), influenciador da lei brasileira de Propriedade Industrial (CERDAN et al. 2014). A partir desses acordos foi possível estruturar o marco conceitual e legal dos assuntos referentes às indicações geográficas.

Segundo os TRIPS/ADIPC, as IGs são

[...] Indicações que identifiquem um produto como originário do território de um Membro, ou região ou localidade deste território, quando determinada qualidade, reputação ou outra característica do produto seja essencialmente atribuída a sua origem geográfica (BRASIL, 1994, anexo IC, art. 22).

Esta definição do TRIPS/ADIPC presente no artigo 22 do Decreto de $n^{\circ} 1.355$ de 30 de dezembro de 1994, estabelece que a indicação geográfica representa a identificação de um produto de determinado território, a partir de elementos como a sua qualidade ou reputação, definidos pela sua origem geográfica. A compreensão deste artigo estabelece os critérios gerais para a proteção de uma IG, os quais devem ser seguidos pelos membros do acordo.

Esse entendimento orienta a definição seguida pelo Instituto Nacional da Propriedade Industrial (INPI), órgão responsável pela concessão das IGs no Brasil. No entanto, diferente de outros países, a Lei (brasileira) da Propriedade Industrial - LPI n 9.279, de 14 de maio de 1996, no seu artigo 176 aponta que as indicações geográficas representam um gênero que pode ser especificado através de uma Indicação de Procedência (IP) ou uma Denominação de Origem (DO) (BRASIL, 1996).

As duas espécies de IG adotadas pelo INPI apresentam algumas diferenciações que são determinantes para identificar qual tipo de produto ou serviço será objeto de uma IG. Sobre a IP, entende-se que esta corresponde a um nome geográfico de país, cidade, região ou localidade de seu território, que se tornou conhecido como centro de extração, produção ou fabricação de determinado produto ou de prestação de determinado serviço (INPI, 2019). Neste caso, a notoriedade de um produto se deve ao seu local de produção, logo, o fator histórico, associado ao saber-fazer, é decisivo na construção desse reconhecimento. Por outro lado, a DO é assinalada como o nome geográfico de país, cidade, região ou localidade de seu território, que designe produto ou serviço cujas qualidades ou características se devam exclusiva ou essencialmente ao meio geográfico, incluídos fatores naturais e humanos (INPI, 2019). Nesta espécie de IG é observado que o meio geográfico formado por elementos naturais como altitude, clima, solo, vegetação, etc, e humanos (saber-fazer) são determinantes para a qualidade e singularidade deste produto.

A partir da leitura da definição do TRIPS e do INPI, podemos observar que ambas se assemelham ao associarem a origem geográfica do produto aos aspectos de notoriedade e qualidade. A combinação de elementos humanos e naturais produz uma qualidade e reputação diferenciada. No entanto, este conceito sofreu variações no Brasil já que "[...] o legislador [brasileiro] não internalizou de forma literal a definição de IG contida no ADPIC [...]" (BRUCH, 2013, p. 249 apud CRUZ, 2017, p. 97), pois a legislação brasileira protege 


\section{Produtos potenciais à indicação geográfica no Estado do Pará: Estudo de caso das feiras na cidade de Belém-Pa}

o nome geográfico e a do TRIPS faz referência às "[...] Indicações que identifiquem um produto como originário do território [...]" (BRASIL, 1994, anexo IC, art. 22). Assim, existe a possibilidade de utilizar qualquer nome que indique que um produto é conhecido por causa da sua origem. Outra diferenciação é que a legislação brasileira abrange o setor de serviços, diferentemente do TRIPS.

Para além disso, hodiernamente é atribuída às IGs a potencialidade de valorização dos produtos e dos territórios que utilizam esse signo distintivo, seja uma valorização simbólica, na qual são levados em consideração a história, a natureza, a cultura, os saberes e os modos de produção pertencentes a uma localidade, ou uma valorização monetária possibilitando o aumento dos preços dos artigos e acesso a novos mercados por conta dessas características distintas. Ambas as formas são capazes de promover a valorização geral da cadeia produtiva, incluindo a presença de produtores, comerciantes e consumidores.

As estratégias de agregação de valor, de forma mais ampla, incluem outras maneiras de utilização da indicação geográfica, o que pode ocorrer por meio da criação e estímulo às atividades complementares com os elementos do território (CERDAN, 2014). Assim, compreendemos que as ações e os empreendimentos ligados ao turismo, a apreciação cultural e histórica, a diversidade e a gastronomia local são incentivados e beneficiados quando associados ao signo de IG. Segundo Dullius, Froehlich e Vendruscolo (2008), essa relação acontece porque há um investimento no plano simbólico, enfatizando elementos (i)materiais do território, objetivando alcançar uma identidade territorial capaz de impulsionar ações de desenvolvimento.

O desenvolvimento neste caso está condicionado à escala territorial, por referir-se a uma sociedade que se organiza territorialmente e utiliza os seus recursos locais, objetivando melhoria socioeconômica e a qualidade de vida da população (DALLABRIDA; FERNANDEZ, 2008). Essa noção está inserida nas principais metas das organizações que solicitam o signo de indicação geográfica, pois com o apoio financeiro e instrutivo das instituições de fomento das IGs, podem alcançar uma melhor condição social, econômica e de trabalho entre os membros do território.

No processo de definição, identificação e uso das IG, existe sempre uma grande expectativa quanto aos benefícios que este signo poderá trazer aos seus detentores e ao território. Esse anseio é resultante dos exemplos de sucesso observados em diversas partes do mundo, nas quais a IG reformulou a dinâmica local com vantagens comerciais, culturais, melhoria de vida, etc. Entretanto, essas práticas não acontecem da mesma maneira em todos os espaços, podendo ocorrer inclusive efeitos negativos.

Esses resultados adversos representam os riscos existentes no processo de reconhecimento de uma Indicação Geográfica. As pesquisas apontam que em alguns casos o principal elemento ameaçador é a falta de coesão entre os agentes, sejam esses os sujeitos produtores ou aqueles pertencentes às instituições de apoio (CRUZ, 2017). Todos os envolvidos no projeto devem trabalhar coletivamente, especialmente os produtores, responsáveis por diversas funcionalidades, como a organização do projeto, escolha das lideranças, definição em conjunto da área de abrangência, constituição de um regulamento de uso que represente o saber-fazer do grupo, além do planejamento pós- registro de IG.

As ações que contrariam essas medidas comprometem as expectativas dos que almejam o registro, tornando o procedimento desestimulante e cansativo. As condições financeiras dos produtores é um outro fator que deve ser levado em consideração durante o processo de reconhecimento de IG, pois o signo também pode 


\section{Produtos potenciais à indicação geográfica no Estado do Pará: Estudo de caso das feiras na cidade de Belém-Pa}

se tornar excludente. Há situações em que o saber-fazer é o mesmo, no entanto, somente uma parte dos produtores possuem condição de seguir as regras para a utilização da IG. Daí Cruz (2017) apontar a importância de se observar as assimetrias socioeconômicas e de poder entre os agentes envolvidos.

\section{CONTEXTO DAS INDICAÇÕES GEOGRÁFICAS NO BRASIL}

O Brasil é conhecido mundialmente pela grande diversidade de elementos encontrados em sua extensa área territorial de $8.510 .820,623 \mathrm{~km}^{2}$ (IBGE, 2018). Essa variação é decorrente de processos naturais envolvendo os fenômenos climáticos, pedológicos e vegetativos, como igualmente provem das ações humanas que se expressam em técnicas específicas e no manuseio de plantas e animais. Sendo assim, as características particulares de cada região do país derivam das diversas tradições e culturas repassadas por seus antecessores, sejam esses indígenas, europeus, asiáticos ou outros. Essa diversidade resulta em produtos com historicidade, tipicidade e qualidade singulares, mas que em função de determinados marcos normativos foram invisibilizados. Entretanto, a partir de 1990, a dimensão tradicional tornou-se uma oportunidade de negócios frente ao avanço econômico no campo e, assim, uma aliada no desenvolvimento sustentável (NUNES; BANDEIRA; NASCIMENTO, 2012). Desde modo, produtos típicos passaram a agregar valor cultural e econômico, sendo capazes de tornar um território famoso por produzir um determinado bem que se distingue pela qualidade, história, tradição, técnica, de outros similares.

Existe uma vasta quantidade de produtos brasileiros que possuem estas características, devido a isso é possível observar que, com os passar dos anos, ocorreu um aumento no número de produtores que obtiveram a concessão do registro de IG e a busca por esse reconhecimento. Esse crescimento ocorreu, principalmente, a partir de 2011/2012, pois houve um maior interesse nessa temática, seja no âmbito acadêmico, institucional e pelo setor agropecuário brasileiro (CRUZ, 2017).

No banco de dados do INPI (2020) ${ }^{4}$, há um total de setenta (70) Indicações Geográficas nacionais, sendo treze (13) Denominações de Origem e cinquenta e sete (57) Indicação de Procedência. No Quadro 01 podemos ter uma visão geral de todas as IGs segundo os tipos de classificação dos produtos, nome da IG, a espécie (IP e DO), estado do qual é proveniente e o ano de concessão do registro. 


\section{Produtos potenciais à indicação geográfica no Estado do Pará: Estudo de caso das feiras na cidade de Belém-Pa}

Quadro 01- Produtos e serviços brasileiros registrados como IG pelo INPI até 10/07/2020

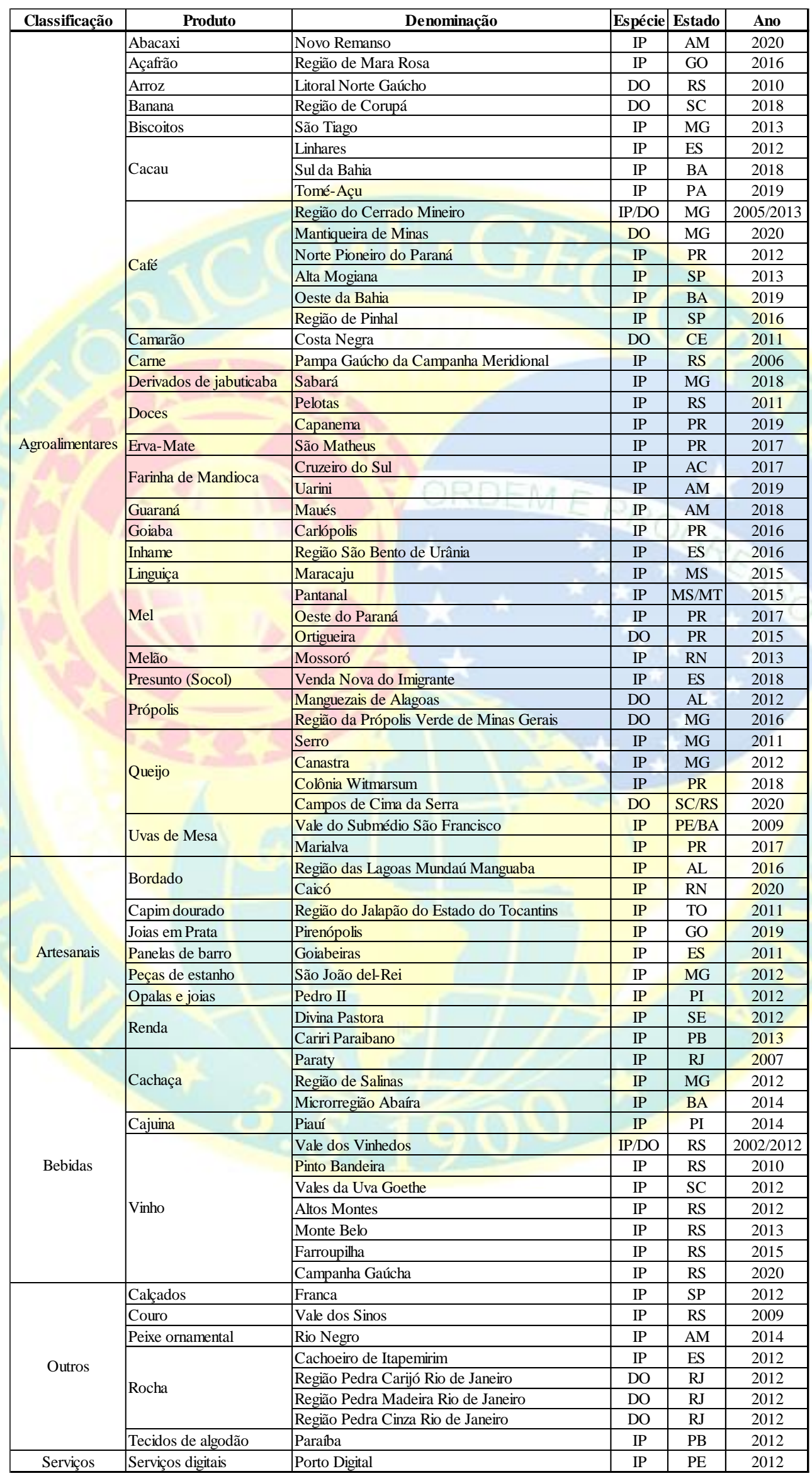

Fonte: INPI (2020). Adaptado por Silva e Cruz (2020). 


\section{Produtos potenciais à indicação geográfica no Estado do Pará: Estudo de caso das feiras na cidade de Belém-Pa}

A partir desses dados, é possível identificar os principais segmentos que buscam o reconhecimento nacional de Indicação Geográfica. Inicialmente é notório o destaque aos produtos agroalimentares com quarenta (40) registros, representando assim, 57,14 \% do número total de IGs. Essas informações demonstram a rica diversidade alimentícia no Brasil, incluindo itens prontos para o consumo, além de muitos produtos in natura, que poderão passar por processos de transformação dentro da cadeia produtiva em que estão inseridos, tendo potencial de agregar valor ao produto final.

Dentro desta classificação agroalimentar, observamos que a produção cafeeira é uma das subcategorias com mais Indicações Geográficas, composta por sete (07) produtos $^{5}$, na qual cinco (05) são IP e duas são (02) DO. Evidentemente a presença deste signo está concentrada na região Sudeste, especificamente nos estados de Minas Gerais e São Paulo, estados com trajetória histórica na cafeicultura e que atualmente ainda se destacam como grandes produtores (MAPA, 2019). No caso de Minas Gerais, a ocorrência deste resultado se deve a grande participação governamental e privada com a criação de programas voltadas ao estímulo da produção de café especial com alto grau de qualidade, objetivando a ascensão do seu produto nos mercados (inter) nacionais (MAMONTOW, 2003).

As bebidas vêm em segundo lugar com 12 registros, sendo onze (11) IP e uma (01) DO. Inegavelmente, os vinhos são os produtos mais expressivos pela quantidade de IGs reconhecidas, cerca de oito (08) produtos divididos em sete (07) IP e uma (01) DO. Quase todas as indicações geográficas pertencem ao estado do Rio Grande do Sul, com exceção da IP Vales da Uva Goethe localizada em Santa Catarina. O setor vinícola é detentor da primeira Indicação Geográfica do Brasil, a IP Vale dos Vinhedos, concedida à Associação de Produtores de Vinhos Finos do Vale dos Vinhedos - APROVALE em 2002, posteriormente, em 2012, a mesma associação adquiriu o signo de DO aos seus vinhos e espumantes (INPI, 2020). O caso dos Vales dos Vinhedos é considerado uma das experiências brasileiras de grande relevância, por conta das consequências sociais e espaciais de suas ações, e por isso é objeto de reconhecimento tanto por outras associações, quanto pelas instituições de pesquisas. Falcade (2005) e Dullius (2009) retrataram como se deu esse processo, os desafios e seus resultados. Para os autores, a cooperação entre os associados permitiu a formação de uma cadeia que possibilita agregação de valor aos diferentes empreendimentos presentes no território, valorização da paisagem da Serra Gaúcha e da gastronomia. Pecqueur (2005) denomina essa experiência como sendo uma "cesta de bens", visto que um produto com qualidade territorial, o vinho, é o indutor de consumo de outros bens presentes nesse território.

\section{PRODUTOS POTENCIAIS PARA IGS ENCONTRADOS NA FEIRA DA 25 E VER O PESO EM BELEM/PA}

A entrada do Pará no mundo das indicações geográficas é relativamente recente e ainda envolto em desconhecimento e curiosidade por parte de alguns setores, seja no âmbito institucional ou da sociedade como

5 O nome geográfico "Região do Cerrado Mineiro" obtém dois (02) registros de indicação geográfica, uma corresponde à Indicação de Procedência reconhecida no ano de 2005 e a outra se refere a Denominação de Origem reconhecida em 2013. 


\section{Produtos potenciais à indicação geográfica no Estado do Pará: Estudo de caso das feiras na cidade de Belém-Pa}

um todo. Dessa forma, tanto produtores quanto consumidores não sabem ou confundem este signo distintivo, suas especificações e funcionalidades.

$\mathrm{Na}$ área acadêmica, a situação não é muito diferente, resultado das poucas pesquisas e produções científicas nessa temática, principalmente aquelas direcionadas aos produtos paraenses. Algumas obras, como as dissertações de Valente (2012), Oliveira (2015) e Santos (2016), juntamente com a tese de doutorado de Cruz (2017) merecem destaque por serem as pioneiras ao tratar dessa temática de modo mais aprofundado, enfatizando elementos do geral e do particular, visto que cada um dos autores (as) se dedica ao estudo de um determinado produto, apontando sua origem, suas características diferenciais, os produtores e o planejamento para a obtenção do signo. ${ }^{6}$

Nos últimos anos houve progressiva atuação das instituições públicas e privadas trabalhando em prol de medidas que visem o reconhecimento e divulgação dos produtos paraenses potenciais ao uso de IGs. Uma das formas mais adotadas é a realização de palestras em seminários, eventos gastronômicos e feiras de empreendimentos. Nesses eventos reúnem-se os atores sociais integrantes dos projetos, produtores, comerciantes, pesquisadores, apoiadores, além de consumidores e de outros sujeitos que se interessarem pela temática.

No ano de 2016, a realização do evento gastronômico Ver-o-Peso da Cozinha Paraense, promovido pelo Instituto Paulo Martins e pelo Projeto do Centro Global de Gastronomia e Biodiversidade da Amazônia, tornou-se um marco importante na história das IGs no estado, pois juntamente com este evento, ocorreu o primeiro Seminário de Identificação Geográfica do Estado do Pará. O evento contou com o apoio de diversas entidades, como a Rede de Núcleos de Inovação Tecnológica da Amazônia Oriental (REDENAMOR), MAPA, SETUR, SEDAP, Museu Emílio Goeldi e SEBRAE.

Esse seminário propiciou debates e estimulou ações em torno dos produtos que são potenciais a uma IG. Entre as medidas discutidas esteve a criação de um fórum específico sobre Indicação Geográfica. No mesmo ano, em 2016, por meio da Portaria de N³38/2016/SETUR, foi criado o Fórum Técnico de Indicação Geográfica e Marcas Coletivas do estado do Pará, cuja a finalidade consiste em

Estudar, deliberar e propor diretrizes e políticas governamentais para a implantação de uma Política Estadual de Indicações Geográficas, criando normas e padrões compatíveis com o Plano Estratégico de Turismo do Estado do Pará e demais instrumentos de planejamento norteadores das atividades afins com o tema (PARÁ, 2016).

Desde então, o fórum tem se empenhado em discutir e propor diretrizes e políticas públicas que envolvam e incentivem as Indicações Geográficas e as Marcas Coletivas no estado. Entre os membros estão incluídos representantes do poder público dos órgãos federais, estaduais, municipais, instituições de pesquisa e ensino, tanto públicas quanto privadas, e organizações não governamentais. As ações do fórum estão progredindo na medida em que os objetivos são alcançados e mais parcerias são firmadas.

\footnotetext{
6 Salientamos que na restrita bibliografia acadêmica das Indicações Geográficas referentes ao estado do Pará encontramos outras produções científicas nos formatos de artigos científicos (Cruz e Hespanhol (2018), Wanghon e Costa (2004), Silva e Assis (2018)) e resumos expandidos (Cruz (2017), Silva (2018), Cruz, Almeida e Silva (2019)) que também são de fundamental importância e contribuem para o desenvolvimento da pesquisa na temática.
} 


\section{Produtos potenciais à indicação geográfica no Estado do Pará: Estudo de caso das feiras na cidade de Belém-Pa}

Algumas das principais diretrizes propostas consistem em acompanhar e apoiar os projetos de IG já em andamento, além de diagnosticar novos produtos potenciais. As primeiras pesquisas para identificar potencialidades no estado do Pará foram realizadas por Gollo e Castro (2008) e mencionam produtos como a Castanha do Pará, Cachaça de Abaeté, Farinha de Bragança, Açaí do Pará ou Marajó, Gurijuba de Vigia, Queijo Marajoara, Caranguejo de São Caetano de Odivelas. Além desses, o MAPA também identificou alguns produtos potenciais incluindo a presença de artesanato, frutas, farinhas, fibra, grão, laticínio, semente e pescado (ver Quadro 02).

Quadro 02 - Produtos identificados como potenciais à Indicação Geográfica no Pará pelo MAPA

\begin{tabular}{|l|l|}
\hline Produtos & Classificação \\
\hline Abacaxi do Marajó & Fruta \\
\hline Açaí das Ilhas de Belém & Fruta \\
\hline Açaí de Igarapé-Miri & Fruta \\
\hline Açaí do Marajó & Fruta \\
\hline Artesanato em Miriti de Abaetetuba & Artesanato \\
\hline Cacau da Transamazônica ou Medicilândia & Fruta \\
\hline Cacau de Cametá & Fruta \\
\hline Cacau de Tomé-Açu & Fruta \\
\hline Castanhas de Oriximiná & Semente \\
\hline Chocolate do Combu & Fruta Processada \\
\hline Farinha de Mandioca de Bragança & Farinha \\
\hline Farinha de Peixe de Piracuí de Santarém & Farinha \\
\hline Farinha de Tapioca de Americano & Farinha \\
\hline Feijão Caupi da Bragantina & Grão \\
\hline Fibra de Curauá de Santarém & Fibra \\
\hline Miriti de Abaetetuba & Fruta \\
\hline Pirarucu Defumado de Santarém & Pescado \\
\hline Queijo do Arquipélago do Marajó & Laticínio \\
\hline
\end{tabular}

Fonte: MAPA/CIG (2019). Adaptado por Silva e Cruz (2020).

Do total de dezoito (18) produtos potenciais, nota-se a predominância de produtos agroalimentares, principalmente frutas, à exceção do Artesanato de Miriti de Abaetetuba e da Fibra de Curauá de Santarém. Na relação dos produtos apontados por Gollo e Castro (2008) e pelo MAPA (2020), observa-se a identificação de três (03) produtos iguais, o Açaí do Marajó, a Farinha de Mandioca de Bragança e o Queijo do Arquipélago do Marajó. Esta repetição expressa o alto grau de reconhecimento que estas localidades têm em função da produção desses alimentos. A Farinha de Bragança e o Queijo do Marajó tipificam na prática essa notoriedade, pois muitos consumidores frequentemente associam esses produtos à região produtora, em razão da qualidade que é atribuída aos mesmos. O resultado da fusão, entre o nome geográfico e o produto, contribuiu para o 


\section{Produtos potenciais à indicação geográfica no Estado do Pará: Estudo de caso das feiras na cidade de Belém-Pa}

desenvolvimento dos primeiros projetos de Indicação Geográfica no Pará direcionados ao Queijo do Marajó e à Farinha de Bragança. Somados a esta categoria de projetos iniciais, incluímos também o planejamento realizado para a obtenção da IP Tomé-Açu, referente à produção de cacau no município, única IG no estado até o momento (julho de 2020). Estes projetos objetivam utilizar os recursos de um território, identificáveis devido a suas características qualitativas próprias, e transformá-los em ativos específicos por meio dos processos de valorização ou especificação, resultando em ações que promovam o desenvolvimento territorial (DULLIUS, FROEHLICH E VENDRUSCOLO, 2008).

Como pode ser observado, três (03) dos dezoito (18) itens da lista do MAPA avançaram no seu processo de reconhecimento junto ao INPI. Iniciado em 2013, o projeto da IG do Queijo do Marajó é considerado um dos mais antigos e conta com o apoio de instituições como SEDAP, Agência de Defesa Agropecuária do Estado do Pará (ADEPARÁ), SEBRAE, MAPA e SETUR. O grande apoio ao projeto é resultante de questões políticas, intensificados pela necessidade de projetos que auxiliem no desenvolvimento socioeconômico e enfrentamento dos baixos Índices de Desenvolvimento Humano presentes na região. Para além desses motivos, existe a necessidade de proteção do nome geográfico Marajó, pois há localidades no estado do Pará que produzem queijo de búfala e utilizam de forma indevida o nome geográfico Marajó em seus produtos (CRUZ, 2017).

Esses fatores influenciaram na organização dos produtores de queijo e leite dos municípios de Cachoeira do Arari, Santa Cruz do Arari, Chaves, Muaná, Ponta de Pedras, Salvaterra e Soure, representados pela Associação dos Produtores de Leite e Queijo do Marajó (APLQM), a trabalharem junto com as instituições de apoio em prol da obtenção do signo de IG. Passados cinco anos depois do início do projeto, em 29 de dezembro de 2018 a APLQM depositou o dossiê no INPI (INPI, 2020). Atualmente o processo está em fase de análise de mérito e aguardando ajustes no dossiê (RPI N²580, 2020).

A iniciativa de proteger a origem da farinha da região bragantina pertence aos produtores dos municípios de Augusto Corrêa, Bragança, Santa Luzia do Pará, Tracuateua e Viseu. De acordo com as entrevistas realizadas por Oliveira (2015) com alguns farinheiros, foi relatado que, em 2011, após uma visita aos locais de comercialização, eles observaram na prática a falsificação do produto, a partir disso intensificaram os debates para proteção do produto.

Em 2013 houve a realização de um workshop sobre a agregação de valor à farinha bragantina, organizado pela SETUR e Secretaria de Estado de Ciência, Tecnologia e Inovação (SECTI). Em reunião posterior a esse evento, definiram a entidade proponente pelo pedido e organizaram um grupo de trabalho composto inicialmente pela Cooperativa Mista de Agricultores e Extrativistas dos Caetés (COOMAC), SETUR Bragança, ADEPARÁ, Secretaria Municipal de Agricultura (SEMAGRI), EMATER, Sindicato dos Trabalhadores e Trabalhadoras Rurais de Bragança (STTR) e Prefeitura de Bragança, para gerir os requisitos necessários à obtenção da IG (OLIVEIRA, 2015).

De 2013 a 2019 o grupo de trabalho realizou uma intensa pesquisa sobre a produção da farinha na região de Bragança, objetivando conhecer a organização produtiva, os modos de produção, mapeamento dos produtores e catalogação de documentos. Essas medidas serviram para a elaboração do regulamento de uso, estrutura de controle, delimitação da área, memorial descritivo, plano de ação a curto e médio prazo. Ademais, 


\section{Produtos potenciais à indicação geográfica no Estado do Pará: Estudo de caso das feiras na cidade de Belém-Pa}

esse trabalho permitiu identificar as principais dificuldades e encontrar soluções de forma coletiva. O resultado de todo esse processo de organização social e institucional possibilitou que, em 05 de janeiro de 2019, a COOMAC depositasse o projeto para apreciação do INPI. Atualmente o projeto encontra-se em fase final de análise documental (RPI N²581, 2020).

Por fim, chegamos ao primeiro registro de IG no Pará, a Indicação de Procedência Tomé-Açu, voltada para a produção de cacau. Os colonos Japoneses iniciaram essa atividade em 1930, porém a mesma ocorreu de forma descontinuada. A partir de 1970 houve a sua retomada, passando por um processo de intensificação na produção cacaueira devido ao aprimoramento de técnicas de cultivo denominada Sistema Agroflorestal de Tomé-Açu (SAFTA) (INPI, 2019).

A notoriedade do cacau produzido em Tomé-Açu se expandiu, principalmente, após a participação do produto na Feira Internacional do Cacau em Paris no ano de 2013, na qual o produto foi classificado como um cacau fino do Pará (SHIBATA, 2019). O presidente da ACTA destaca também que a comercialização da Cooperativa Agrícola Mista de Tomé-Açu (CAMTA) ${ }^{7}$ com a empresa japonesa Meiji influenciou a busca pela IG, pois assim há uma confirmação da qualidade e da origem das amêndoas paraenses que são exportadas para o Japão.

Em virtude disso, a ACTA juntamente com a CAMTA, a Universidade de Tóquio, a Agência de Cooperação Internacional do Japão (JICA) e a parceria com a Universidade Estadual Paulista (UNESP) elaboraram o projeto e o dossiê para a obtenção da indicação de procedência depositado no INPI em 28 de outubro de 2014. Desde então o projeto passou por vários ajustes e em 29 de janeiro de 2019 foi concedido o registro pelo INPI (CRUZ, 2017; INPI, 2019).

Entende-se que embora a associação já detenha o signo de IG, ainda são necessárias a adoção de medidas que promovam a divulgação e agreguem valor ao produto e ao seu território. Em decorrência disso, a ACTA, em parceria com entidades do Fórum Técnico de Indicação Geográfica e Marcas Coletivas do Pará (FTIGMC), como o SEBRAE e a SEDAP, trabalha para expandir a importância da IG Tomé-Açu, caracterizando-a como um ativo específico capaz de contribuir para a valorização da história da imigração japonesa, o conhecimento dos produtores, assim construir uma identidade territorial que auxilie no desenvolvimento dessa cadeia produtiva e do território da IG.

Para além desses produtos, na pesquisa que realizamos foi possível identificar um total de quarenta e cinco (45) produtos conhecidos por sua de origem territorial de produção. (Quadro 03).

7 A ACTA (Associação dos Comerciantes de Tomé-Açu) é o braço associativo da CAMTA (Cooperativa Agrícola Mista de Tomé-Açu). 


\section{Produtos potenciais à indicação geográfica no Estado do Pará: Estudo de caso das feiras na cidade de Belém-Pa}

Quadro 03 - Produtos potenciais a IGs encontrados nas feiras da 25 e no Ver o Peso - Belém

\begin{tabular}{|c|c|c|c|c|c|}
\hline \multirow{2}{*}{$\mathbf{N}^{\circ}$} & \multirow{2}{*}{ Produtos } & \multirow{2}{*}{ Classificação } & \multicolumn{2}{|c|}{$\begin{array}{l}\text { Encontrado na } \\
\text { Feira }\end{array}$} & \multirow{2}{*}{ Fonte } \\
\hline & & & 25 & Ver o Peso & \\
\hline 1 & Abacaxi do Marajó & Fruta & $\mathrm{X}$ & $\mathrm{X}$ & MAPA \\
\hline 2 & Açaí das Ilhas de Belém & Fruta & $X$ & & $\begin{array}{l}\text { MAPA/SETUR/ } \\
\text { FÓRUM/SEBRAE }\end{array}$ \\
\hline 3 & Açaí de Abaetetuba & Fruta & $\mathrm{X}$ & & Trabalho de campo \\
\hline 4 & Açaí de Cametá & Fruta & & & MAPA \\
\hline 5 & Açaí de Igarapé-Miri & Fruta & & & MAPA \\
\hline 6 & Açaí do Marajó & Fruta & & & MAPA \\
\hline 7 & Apaiari do Marajó & Pescado & & $\mathrm{X}$ & Trabalho de campo \\
\hline 8 & Aracu do Marajó & Pescado & & $\mathrm{X}$ & Trabalho de campo \\
\hline 9 & $\begin{array}{l}\text { Artesanato em Miriti de } \\
\text { Abaetetuba }\end{array}$ & Artesanato & & & $\begin{array}{l}\text { MAPA/SETUR/ } \\
\text { FÓRUM/SEBRAE }\end{array}$ \\
\hline 10 & $\begin{array}{l}\text { Cacau da Transamazônica ou } \\
\text { Medicilândia }\end{array}$ & Fruta & & & MAPA \\
\hline 11 & Cacau de Cametá & Fruta & & & MAPA \\
\hline 12 & $\begin{array}{l}\text { Castanhas de Oriximiná } \\
\text { (Calha Norte do Amazonas) }\end{array}$ & Castanha & & & $\begin{array}{l}\text { MAPA/SETUR/ } \\
\text { FÓRUM/SEBRAE }\end{array}$ \\
\hline 13 & Chocolate do Combu & Chocolate & & & MAPA \\
\hline 14 & Cuias de Aritapera & Artesanato & & & SETUR/SEBRAE \\
\hline 15 & $\begin{array}{l}\text { Farinha d'agua comum de } \\
\text { Irituia }\end{array}$ & Farináceos & $\mathrm{X}$ & $\mathrm{X}$ & Trabalho de campo \\
\hline 16 & Farinha d'água de São Miguel & Farináceos & $\mathrm{X}$ & $\mathrm{X}$ & Trabalho de campo \\
\hline 17 & $\begin{array}{l}\text { Farinha d'água lavada de } \\
\text { Irituia }\end{array}$ & Farináceos & $X$ & $\mathrm{X}$ & Trabalho de campo \\
\hline 18 & $\begin{array}{l}\text { Farinha de macaxeira de São } \\
\text { Miguel }\end{array}$ & Farináceos & $\mathrm{X}$ & & Trabalho de campo \\
\hline 19 & $\begin{array}{l}\text { Farinha de mandioca de } \\
\text { Bragança d'água comum }\end{array}$ & Farináceos & $\mathrm{X}$ & $\mathrm{X}$ & Trabalho de campo \\
\hline 20 & $\begin{array}{l}\text { Farinha de mandioca de } \\
\text { Bragança lavada }\end{array}$ & Farináceos & X & & MAPA/SEBRAE \\
\hline
\end{tabular}




\section{Produtos potenciais à indicação geográfica no Estado do Pará: Estudo de caso das feiras na cidade de Belém-Pa}

\begin{tabular}{|c|c|c|c|c|c|}
\hline 21 & $\begin{array}{l}\text { Farinha de mandioca São } \\
\text { Miguel }\end{array}$ & Farináceos & & $\mathrm{X}$ & Trabalho de campo \\
\hline 22 & $\begin{array}{l}\text { Farinha de Peixe de Piracuí de } \\
\text { Prainha }\end{array}$ & Farináceos & $X$ & $\mathrm{X}$ & FÓRUM \\
\hline 23 & $\begin{array}{l}\text { Farinha de Tapioca de } \\
\text { Americano }\end{array}$ & Farináceos & $\mathrm{X}$ & $\mathrm{X}$ & $\begin{array}{l}\text { MAPA/SETUR/ } \\
\text { FÓRUM/SEBRAE }\end{array}$ \\
\hline 24 & Farinha seca de São Miguel & Farináceos & $\mathrm{X}$ & & Trabalho de campo \\
\hline 25 & Farinha torrada de Bragança & Farináceos & & $\mathrm{X}$ & Trabalho de campo \\
\hline 26 & Farinha torrada de Irituia & Farináceos & $\mathrm{X}$ & $\mathrm{X}$ & Trabalho de campo \\
\hline 27 & Feijão Caupi da Bragantina & Grão & $\mathrm{X}$ & $\mathrm{X}$ & MAPA \\
\hline 28 & $\begin{array}{l}\text { Feijão Manteiguinha de } \\
\text { Santarém }\end{array}$ & Grão & $\mathrm{X}$ & $\mathrm{X}$ & SETUR/ FÓRUM \\
\hline 29 & Fibra de Curauá de Santarém & Fibra & & & MAPA \\
\hline 30 & Filhote de Mosqueiro & Pescado & & $\mathrm{X}$ & Trabalho de campo \\
\hline 31 & Mapará de Cametá & Pescado & $\mathrm{X}$ & $\mathrm{X}$ & Trabalho de campo \\
\hline 32 & Mel de Pirabas & Mel & $\mathrm{X}$ & & SETUR/ FÓRUM/ SEBRAE \\
\hline 33 & Mel do Marajó & Mel & $\mathrm{X}$ & & Trabalho de campo \\
\hline 34 & Miriti de Abaetetuba & Fruta & & $\mathrm{X}$ & MAPA \\
\hline 35 & Ostras do Salgado & Frutos do Mar & & & FÓRUM \\
\hline 36 & Pescada Amarela de Soure & Pescado & & $\mathrm{X}$ & Trabalho de campo \\
\hline 37 & Pescada Branca de Soure & Pescado & & $\mathrm{X}$ & Trabalho de campo \\
\hline 38 & $\begin{array}{l}\text { Pimenta do Reino de Tomé- } \\
\text { Açu }\end{array}$ & Especiaria & $\mathrm{X}$ & & FÓRUM \\
\hline 39 & Piramutaba de Vigia & Pescado & & $\mathrm{X}$ & Trabalho de campo \\
\hline 40 & $\begin{array}{l}\text { Pirarucu defumado de } \\
\text { Santarém }\end{array}$ & Pescado & $\mathrm{X}$ & & MAPA/SETUR \\
\hline 41 & $\begin{array}{l}\text { Queijo do Arquipélago do } \\
\text { Marajó }\end{array}$ & Laticínio & $\mathrm{X}$ & $\mathrm{X}$ & $\begin{array}{l}\text { MAPA/SETUR/ } \\
\text { FÓRUM/SEBRAE }\end{array}$ \\
\hline 42 & Tamuatá do Marajó & Pescado & & $\mathrm{X}$ & Trabalho de campo \\
\hline 43 & Tucupi de Bragança & Sumo & & & SEBRAE \\
\hline 44 & Tucupi de Santa Isabel & Sumo & $\mathrm{X}$ & & Trabalho de campo \\
\hline 45 & Tucupi de Vigia & Sumo & & & SETUR/ FÓRUM \\
\hline
\end{tabular}

Fonte: SEBRAE (2018). SETUR (2018). Trabalho de Campo (2019). FTIGMC (2020). MAPA (2020). Adaptado por Silva e Cruz (2020). 


\section{Produtos potenciais à indicação geográfica no Estado do Pará: Estudo de caso das feiras na cidade de Belém-Pa}

Analisando os dados do Quadro 03 observamos a existência de vinte (20) novos produtos potenciais pertencentes a diferentes territórios que não constam na lista dos órgãos oficiais ligados ao FTIGMC. As classificações que mais se destacaram devido ao reconhecimento da origem geográfica foram os pescados e os farináceos. Além desses, foram encontrados em menores proporções sumo, fruta e mel.

Identificamos um total de oito (08) espécies de peixes, a maioria pertencente a Ilha do Marajó, com exceção de três (03) produtos oriundos de outras localidades como Mosqueiro, Cametá e Vigia. A respeito dos farináceos foram encontrados nove (09) tipologias de farinhas: no município de Irituia estão denominadas a Farinha d'agua comum, d'agua lavada e torrada; as originarias de São Miguel do Guamá são a Farinha d'agua, macaxeira, mandioca e seca; e, por fim em Bragança encontramos as farinhas de mandioca d'agua comum e a torrada. Utilizamos essas informações para elaborar o Quadro 04 e demonstramos como esses dados estão distribuídos.

Quadro 04 - Distribuição dos produtos encontrados

\begin{tabular}{|l|c|c|c|c|c|}
\hline \multicolumn{5}{|c|}{ Quantidade de produtos encontrados } \\
\hline & Feira da 25 & Feira do Ver o Peso & Ambas as feiras & Não encontrados & Novos produtos \\
\hline Total & 22 & 22 & 12 & 13 & 20 \\
\hline
\end{tabular}

Fonte: SEBRAE (2018). SETUR (2018). Trabalho de Campo (2019). Fórum IG Pará (2020). MAPA (2020). Adaptado por Silva e Cruz (2020)

No quadro anterior temos um panorama sobre a quantidade de produtos encontrados durante o período da pesquisa. Inicialmente notamos que a quantidade de produtos encontrados na Feira da 25 e no Ver o Peso são iguais correspondendo a vinte e dois (22) potenciais. Todos os produtos encontrados pertencem ao gênero alimentício, no entanto, a classificação desses alimentos é variada em cada feira. Na feira da 25 há uma maior distribuição da quantidade de alimentos de acordo com a sua tipologia, considerando a presença de pelo menos um produto em cada classificação. Diferente desta, os produtos encontrados na feira do Ver o Peso são as frutas, farináceos, pescados, grãos e laticínios. Ver Gráfico 01. 


\section{Produtos potenciais à indicação geográfica no Estado do Pará: Estudo de caso das feiras na cidade de Belém-Pa}

Gráfico 01 - Quantidade de produtos nas feiras a partir da sua classificação

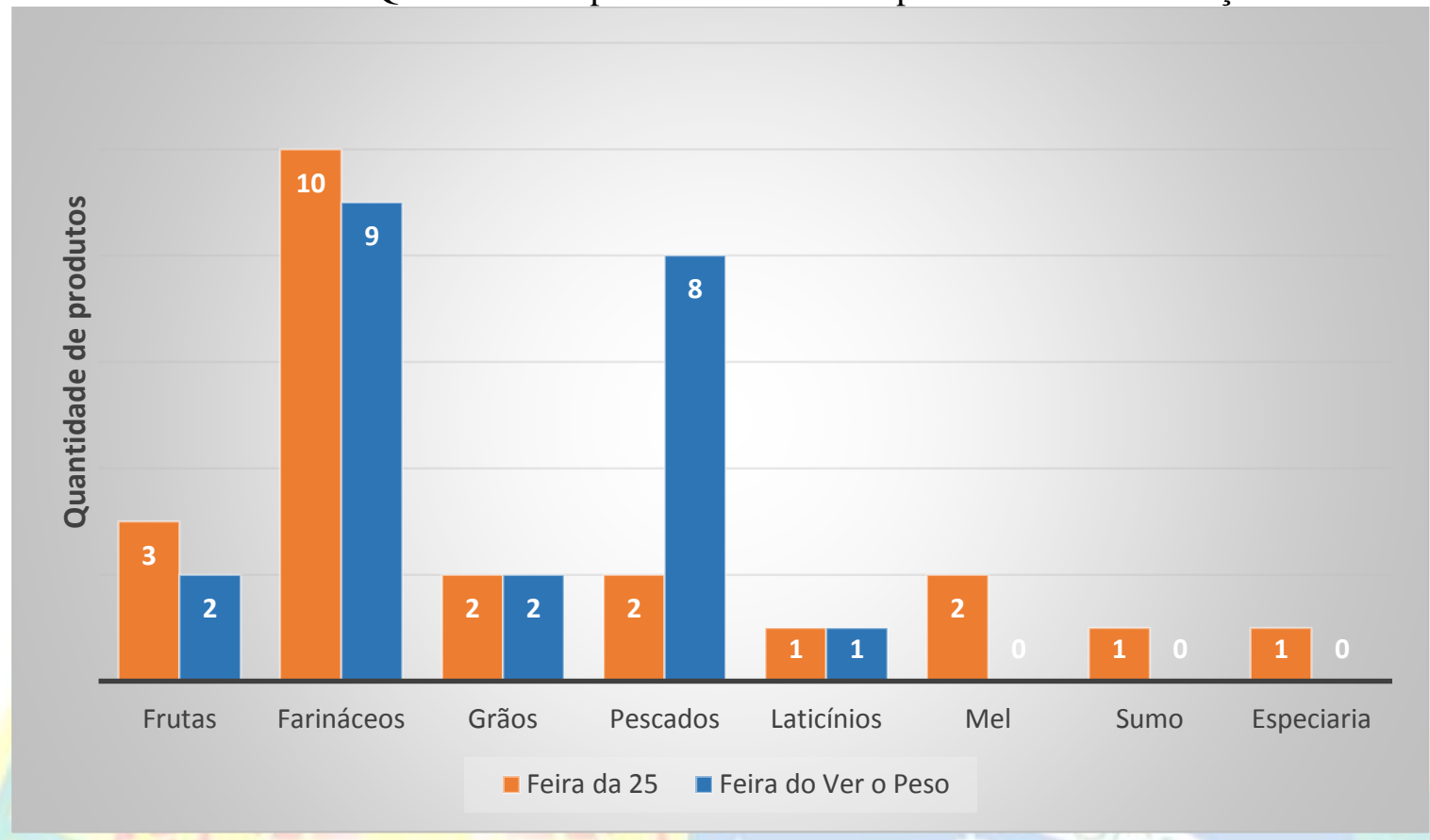

Fonte: SEBRAE (2018). SETUR (2018). Trabalho de Campo (2019). FTIGMC (2020). MAPA (2020). Adaptado por Silva e Cruz (2020)

Nas duas feiras, os farináceos são os produtos que apresentam os maiores valores, desta forma são os mais reconhecidos e identificados conforme a sua procedência, sejam eles originários do município de Bragança, São Miguel do Guamá, Irituia, Americano ou outro. Este resultado é explicado por conta do elevado consumo desses alimentos e pela associação da qualidade com a origem territorial da produção.

Os pescados encontrados na feira do Ver o Peso correspondem a outra classificação em evidencia, visto que foram identificados oito (08) tipos de peixes e os seus respectivos territórios. A utilização da indicação da procedência desses animais como estratégia de diferenciação e atrativo se assemelha com a dos farináceos, sobretudo porque o Ver o Peso, mais especificamente o porto ao lado denominado "Pedra do Peixe", corresponde ao principal local de abastecimento peixeiro de Belém.

Examinando a listagem dos produtos localizados nas duas feiras, percebemos que há cerca de doze (12) produtos que podem ser encontrados em ambas as feiras. Entre esses itens, novamente os farináceos representam o maior número de identificados, correspondendo a sete (07) produtos; em segundo lugar estão os grãos, com dois (02) produtos; e em terceiro temos empatadas as classificações de fruta, pescado e laticínio, apresentando um (01) produto cada. Ressaltamos que quase 50\% desses produtos nomeados, juntamente com a sua origem, foram reconhecidos via pesquisa de campo, a outra metade provém de fontes ligadas aos órgãos que compõe FTIGMC como o MAPA, SETUR e SEBRAE. Sendo assim, entendemos que, embora alguns produtos não estejam incluídos nas tabelas das entidades governamentais de fomento ao signo de IG, eles apareceram no momento da pesquisa de campo, pois são nomeados de acordo com sua origem de produção e são reconhecidos socialmente pelas características advindas dos seus locais de produção.

Em algumas circunstâncias a situação ocorre de maneira adversa, às vezes o produto é reconhecido pelos órgãos institucionais, porém não é encontrado durante a pesquisa em campo. Esse foi o nosso caso, pois 


\section{Produtos potenciais à indicação geográfica no Estado do Pará: Estudo de caso das feiras na cidade de Belém-Pa}

treze (13) produtos caracterizados como potenciais para a IG por alguns componentes do Fórum, não foram encontrados em nenhuma das feiras. Não é possível saber o real motivo da ausência desses produtos, no entanto algumas questões devem ser levadas em consideração na análise, por exemplo: o alcance da notoriedade do produto, seja local ou regional; o espaço que o público consumidor de tal artigo frequenta; o grau de conhecimento do vendedor sobre os seus produtos; a quantidade de locais visitados. Essas e outras reflexões podem influenciar nos resultados da pesquisa, pois cada lugar possui as suas particularidades, sujeitos, dinâmicas e demandas diferentes, assim apesar dele não ter sido identificado em alguns desses espaços, ele pode estar presente e ser notório em outro.

No intuito de demonstrar como o mercado "enxerga" esses produtos, os gráficos 02 e 03 permitemnos uma visão geral da relação produto-origem-consumo. No Gráfico 02 podemos verificar a escolha do consumidor em relação à origem territorial do produto.

Gráfico 02 - Os consumidores escolhem os produtos de acordo com sua origem?

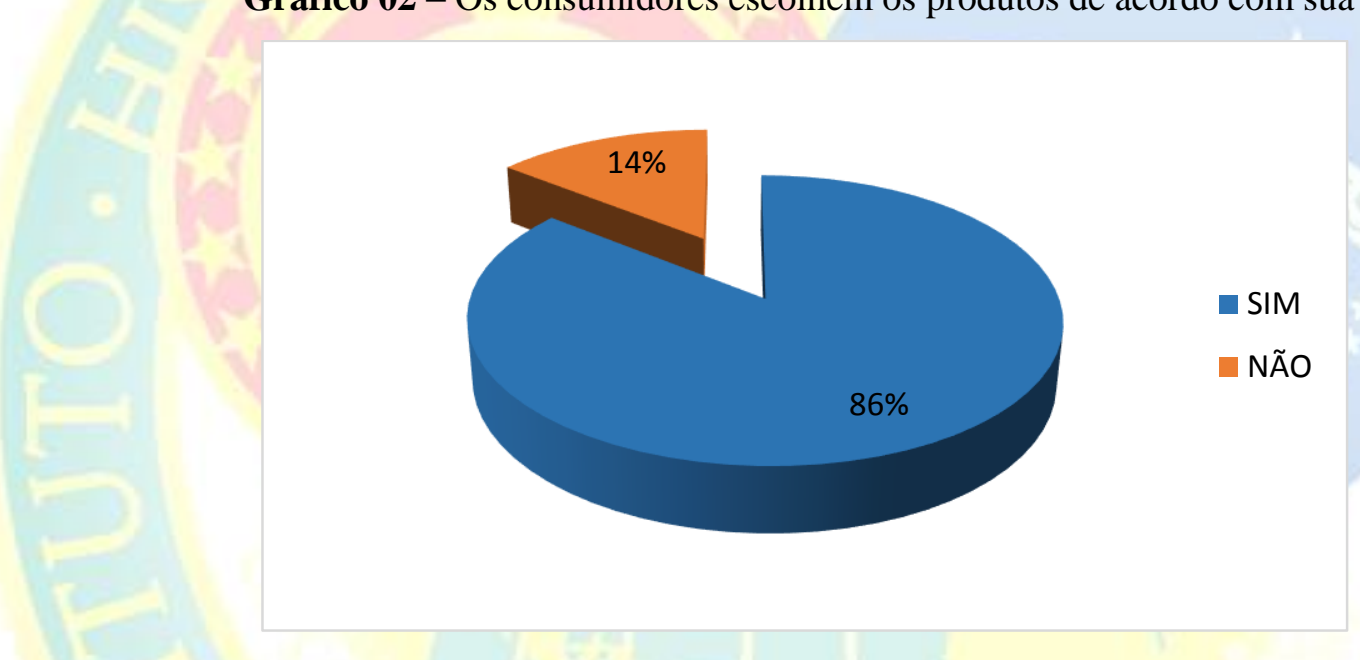

Fonte: Autores (2019).

Observamos que 86\% (30 Feirantes) responderam que sim, os clientes escolhem os produtos por seu local de origem. Já 14\% (5 Feirantes) pensam ao contrário, que os clientes não escolhem os produtos pela origem. Dessa forma, a ampla maioria dos consumidores associa qualidade à origem territorial do produto. Isso fica evidente quando analisamos a relação preço e origem do produto. (Gráfico 03). 


\section{Produtos potenciais à indicação geográfica no Estado do Pará: Estudo de caso das feiras na cidade de Belém-Pa}

Gráfico 03 - O preço do produto e sua origem

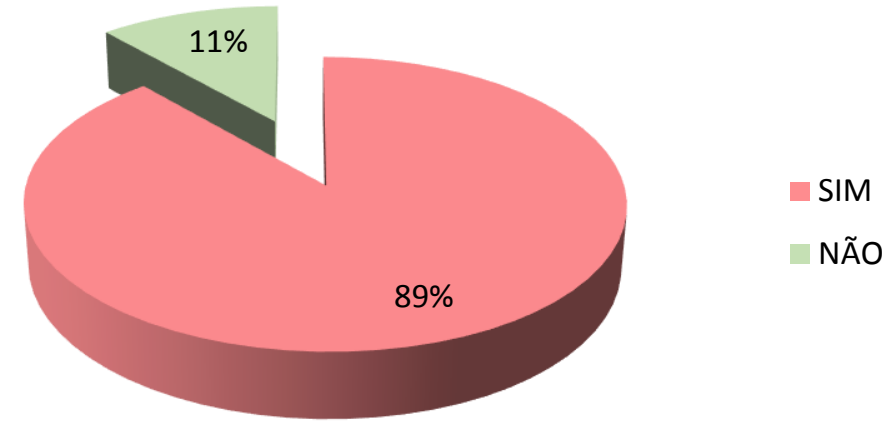

Fonte: Autores (2019).

Novamente a maioria, $89 \%$ (31 Feirantes), respondeu que sim, o preço do produto varia de acordo com a origem, e 11\% (4 Feirantes) acreditam que o preço do produto não varia com a origem de produto. A partir dessas informações, é possível afirmar que ato de indicar a origem territorial do produto pode torna-se uma estratégia de diferenciação e atrativo, devido ao reconhecimento da qualidade associada e a origem do produto.

A (re) valorização dos conhecimentos tradicionais mencionada na obra de Nunes, Bandeira e Nascimento (2012) apontam as IGs como uma das possibilidades para a realização deste objetivo, pois valorizam a diversidade cultural e os potenciais presentes nos territórios, além de considerar o signo de indicação geográfica "[...] uma forma de agregar valor e credibilidade a um produto ou serviço, conferindolhes um diferencial de mercado em função das características de seu local de origem” (Ibidem, p. 347). Esse entendimento é o mesmo compartilhado por Dullius, Froehlich e Vendruscolo (2008) em que é observada a emergência de uma nova ruralidade que valoriza os territórios, protege e agrega valor às populações e aos seus saberes tradicionais.

As pesquisas nas feiras de Belém confirmaram a existência desta diversidade socioprodutiva no estado do Pará, a partir da identificação das diferentes classificações de produtos típicos que podem se tornar uma IG, por apresentarem notoriedade e qualidade devido aos seus atributos naturais e humanos. É perceptível que essas características são capazes de influenciar as escolhas e o preço desses produtos tradicionais, logo, indicam que há um reconhecimento e uma valorização social dos consumidores graças a estes fatores.

\section{CONSIDERAÇÕES FINAIS}

O signo de indicação geográfica passou por diversas transformações, que inclui um extenso processo histórico, institucional e social, que conduziu a definição de princípios, conceitos, usos e riscos, levando a se tornar uma ferramenta de proteção e promoção do desenvolvimento em nível global.

No Brasil, as indicações geográficas apresentam uma grande diversidade classificativa, principalmente em relação aos produtos agroalimentares. A partir de 2012, houve um aumento na obtenção deste signo 


\section{Produtos potenciais à indicação geográfica no Estado do Pará: Estudo de caso das feiras na cidade de Belém-Pa}

distintivo, com destaque para os estados das regiões sul e sudeste. A promoção de produtos com IG, além de agregar valor aos mesmos, possibilita acesso a novos mercados e dinamiza seus espaços de produção. Entretanto, para que isso ocorra é necessário a mobilização de diversos atores sociais e institucionais que pesquisem, estimulem e auxiliem no reconhecimento antes e pós obtenção de IGs e na resolução dos riscos que envolvem este processo.

No estado do Pará, é perceptível a presença de diversos produtos notórios, identificáveis tanto pelos consumidores locais quanto por aqueles de fora do estado. A pesquisa realizada nas feiras da 25 e Ver o Peso em Belém, demonstrou que a origem é um fator que influencia na comercialização dos produtos. Para além dos produtos apontados pelos órgãos oficiais foram identificados vinte (20) novos produtos, de diferentes classificações e que são reconhecidos por sua procedência geográfica. Este resultado demonstra que há produtos que ainda não foram identificados e que podem ser identificados por meio de novas pesquisas. Assim, torna-se importante analisar a identificação de novos produtos potenciais, seu grau de notoriedade e organização socioprodutiva.

A classificação dos produtos potenciais em cada feira demonstra a diversidade de produtos e variação existente. Entretanto, evidenciamos que um dos problemas para agregar valor por meio de uma IG a esses produtos se deve ao fato de que praticamente todos os produtos são comercializados in natura ou com baixo nível de processamento e de valor agregado. Em virtude disso, são necessários maiores esforços para agroindustrialização desses produtos e estratégias de promoção.

Em síntese, concluímos que o estado de Pará possui uma grande quantidade de produtos potenciais específicos que carregam consigo atributos humanos e naturais que "contam" e projetam a geograficidade dos seus espaços. A constituição dos projetos de IGs contribui para a transformação desses bens em ativos territoriais que podem auxiliar nas políticas de desenvolvimento direcionadas para o território. Ressaltamos a necessidades de novas pesquisas para compreender a organização socioprodutiva dos produtos potenciais identificados na pesquisa e que futuramente poderão compor projetos a serem submetidos ao INPI.

\section{REFERENCIAS}

ALMEIDA. Alberto Francisco Ribeiro de. A autonomia jurídica da denominação de origem. Coimbra: Coimbra Editora, 2010. 1476 p.

BRASIL. Presidência da República. Lei 9.279, de 14/05/1996. Regula direitos e obrigações relativas à propriedade industrial. Brasília, maio de 1996.

BRASIL. Decreto $n^{\circ} 1.355$, de 30 de dezembro de 1994. Promulga a Ata Final que Incorpora os Resultados da Rodada Uruguai de Negociações Comerciais Multilaterais do GATT. Anexo IC: Acordo sobre os aspectos dos direitos de propriedade intelectual relacionados ao comércio (ADPIC). Disponível em: <http://www.planalto.gov.br/ccivil_03/decreto/1990-1994/anexo/and1355-94.pdf〉. Acesso em: 26 jun.2020.

BRUCH, Kelly Lissandra et al. Indicações Geográficas e Outros Signos Distintivos: Aspectos Legais. In: BRASIL. Ministério da Agricultura, Pecuária e Abastecimento. Curso de propriedade Intelectual e Inovação no Agronegócio: Indicação geográfica. Florianópolis: FUNJAB, 2014. 2 (p. 62-79). 


\section{Produtos potenciais à indicação geográfica no Estado do Pará: \\ Estudo de caso das feiras na cidade de Belém-Pa}

BRUCH, Kelly Lissandra. A legislação brasileira sobre Indicações Geográficas em face das experiências internacionais. In: NIEDERLE, P. A. (Org.). Indicações Geográficas: Qualidade e Origem nos mercados alimentares. Porto Alegre: Editora da UFRGS, 2013. 3 (p. 245-260).

CERDAN, Claire Marie Thuillier. et al. Indicações geográficas de produtos agropecuários: importância histórica e atual. In: BRASIL. Ministério da Agricultura, Pecuária e Abastecimento. Curso de propriedade Intelectual e Inovação no Agronegócio: Indicação geográfica. Florianópolis: FUNJAB, 2014. 1 (p. 32-53).

CRUZ, Benedito Ely Valente da. O Alvorecer das indicações geográficas na Amazônia: a “corrida” pela IG do queijo artesanal do Marajó - PA. Tese (Doutorado em Geografia) - Faculdade de Ciências e Tecnologia, Universidade Estadual Paulista, Presidente Prudente, 2017. 388 f.

Indicações geográficas na Amazônia: produtos potenciais e projetos em desenvolvimento. In:

VI WORKSHOP CATARINENSE DE INDICAÇÃO GEOGRÁFICA. Joinville. 9, 10 e 11 de agosto de 2017. Anais do VI Workshop catarinense de indicação geográfica. Joinville, SC: Editora UNIVILLE, 2017. (p.8590).

CRUZ, Benedito Ely Valente da.; ALMEIDA, Pedro Henrique Gomes de.; SILVA, Stephanie Oliveira da. Produtos potenciais para indicação geográfica no estado do Pará: estudo de caso dos produtos comercializados na feira da 25, em Belém do Pará. In: VIII WORKSHOP CATARINENSE DE INDICAÇÃO GEOGRÁFICA. Florianópolis. 30 e 31 de outubro de 2019. Anais do VIII Workshop catarinense de indicação geográfica., Florianópolis SC: Edição EPAGRI, 2019. (p. 308-313).

CRUZ, Benedito Ely Valente da.; HESPANHOL, Rosangela Ap. Medeiros. Indicação geográfica e queijos artesanais: marco legal e desafios a uma política para este segmento no Brasil. Confins Revue franco brésilienne de géographie / Revista franco-brasileira de geografia. n. 37. 2018. <Disponível em: https://journals.openedition.org/confins/15222\#article-15222 1/>. Acesso em 15jul. 2019.

DALLABRIDA, Valdir Roque; FERNÁNDEZ, Victor Ramiro. Desenvolvimento territorial: possibilidades e desafios, considerando a realidade de âmbitos espaciais periféricos. Passo Fundo: Editora: UNIJUI, 2008. p. 204.

DULLIUS, Paulo Roberto. Indicações Geográficas e desenvolvimento territorial: as experiências do Rio Grande do Sul. Dissertação (Mestrado em Extensão Rural) - Centro de Ciências Rurais, Universidade Federal de Santa Maria, Santa Maria, 2009. 137 f.

DULLIUS, Paulo Roberto.; FROEHLICH, José Marcos.; VENDRUSCOLO, Rafaela.; Identidade e Desenvolvimento Territorial - Estudo das experiências de Indicações Geográficas no estado do RS. In: XLVI CONGRESSO DA SOBER (SOCIEDADE BRASILEIRA DE ECONOMIA, ADMINISTRAÇÃO E SOCIOLOGIA RURAL. Anais do XLVI congresso da SOBER (Sociedade Brasileira de Economia, Administração e Sociologia Rural). Rio Branco, AC. 20 a 23 de julho de 2008.

FALCADE, Ivanira. Indicações Geográficas, o caso da região como indicação de procedência Vale dos Vinhedos. Dissertação (Mestrado em Geografia) - Instituto de Geociências, Universidade Federal do Rio Grande do Sul. Porto Alegre, RS, 2005. 190 f.

FÓRUM TÉCNICO ESTADUAL DE INDICAÇÕES GEOGRÁFICAS E MARCAS COLETIVAS DO ESTADO DO PARÁ. Regimento interno. 2019. 


\section{Produtos potenciais à indicação geográfica no Estado do Pará: \\ Estudo de caso das feiras na cidade de Belém-Pa}

GOLLO, Silvana Saionara.; CASTRO, Alberto William Viana de. Indicações geográficas no Brasil: as indicações de procedência já outorgadas e as áreas e produtos com potencial de certificação. In: XLVI CONGRESSO DA SOBER (SOCIEDADE BRASILEIRA DE ECONOMIA, ADMINISTRAÇÃO E SOCIOLOGIA RURAL. Anais do XLVI Congresso da sociedade Brasileira de Economia, Administração e Economia Rural. Rio Branco, AC. 20 a 23 de julho de 2008.

INSTITUTO BRASILEIRO DE GEOGRÁFICA E ESTATISTICA, IBGE. Área Territorial: Área territorial brasileira. Rio de Janeiro: IBGE, 2018. Disponível em: 〈https://www.ibge.gov.br/cidades-e-estados〉. Acesso em: 31 mai.2020.

INSTITUTO NACIONAL DA PROPRIEDADE INDUSTRIAL, INPI. Indicação Geográfica no Brasil.

Disponível em: <https://www.gov.br/inpi/pt-br/servicos/indicacoes-geograficas/indicacao-geografica-nobrasil> Acesso 20 mai.2020.

. Pedidos de indicação geográfica concedidos e em andamento. Disponível em:

$<$ http://www.inpi.gov.br/Menu-Servicos/Indicacao-Geografica/Pedidos-De-Indicacao-Geografica-NoBrasil>. Acesso em: 20 mai.2020.

Revista da Propriedade Industrial (RPI) N 2508. 29 de Janeiro de 2019.

Revista da Propriedade Industrial (RPI) $N^{o} 2580.16$ de Junho de 2020.

Revista da Propriedade Industrial (RPI) No 2581. 23 de Junho de 2020.

MAMONTOW, Anatolio. A qualidade como base para a estratégia de diferenciação: um estudo de caso em uma empresa do segmento de cafés gourmet. Dissertação (mestrado profissional) - Faculdade de Engenharia Mecanica, Universidade Estadual de Campinas, Campinas, SP, 2003. 191 f.

MINISTÉRIO DA AGRICULTURA, PECUÁRIA E ABASTECIMENTO, MAPA. Mapa Interativo Signos Distintivos Registrados e Produtos Potenciais. Disponível em: <https://www.gov.br/agricultura/ptbr/assuntos/sustentabilidade/indicacao-geografica/mapa-interativo> Acesso em: 30 mai.2020.

Sumário Executivo Café. Dezembro de 2019. Disponível em:<

http://www.sapc.embrapa.br/arquivos/consorcio/informe_estatistico/Sumario_Cafe_Dezembro_2019.pdf>.

Acesso em: 17 mai.2020.

NUNES, Gilvanda Silva.; BANDEIRA, Maria da Glória Almeida.; NASCIMENTO, Jaqueline Silva. Indicações geográficas (IGs): instrumento de desenvolvimento sustentável. Revista GEINTEC-Gestão, Inovação e Tecnologias, São Cristóvão/SE, v. 2, n. 4, p. 344-352, 2012.

OLIVEIRA, Amanda Borges de. Indicações Geográficas, Produtos Tradicionais E Desenvolvimento Territorial Na Amazônia: Um olhar sobre o projeto de Indicação Geográfica da farinha de Bragança. Dissertação (Mestrado em Direito) - Instituto de Ciências Jurídicas, Universidade Federal do Pará, Belém do Pará. 2015. 193 f.

PECQUEUR, Bernard. O desenvolvimento territorial: uma nova abordagem dos processos de desenvolvimento para as economias do sul, Raízes, Campina Grande, v. 24, n. 01 e 02, p. 10-22, 2005. SACCARO JUNIOR, Nilo Luiz. A regulamentação de acesso a recursos genéticos e repartição de benefícios: disputas dentro e fora do Brasil. Ambiente \& Sociedade, Campinas, v. XIV, n. 1, p. 229-244, 2011. 


\section{Produtos potenciais à indicação geográfica no Estado do Pará: Estudo de caso das feiras na cidade de Belém-Pa}

SANTOS, Natascha Penna dos. A farinha de Bragança (PA): memorial individual e a construção da identidade patrimonial na região bragantina. Dissertação (Mestrado em Linguagens e Saberes na Amazônia). Programa de Pós-Graduação em Linguagens e Saberes na Amazônia - PPLSA, Universidade Federal do Pará, Bragança, PA. 2016. 106 f.

SHIBATA, Silvio. Palestra sobre a Experiência da IG Tomé- Açu referente a produção de cacau. VI FESTIVAL INTERNACIONAL DO CHOCOLATE E CACAU, E FLOR PARÁ. Belém, 2019.

SILVA, Lidenilson Sousa da.; ASSIS, William Santos de. Farinha de Bragança: identificação geográfica como estratégia camponesa de valorização dos produtos da Amazônia. In: X Congreso de la Asociación Latinoamericana de Sociología Rural (ALASRU) "Ruralidades en América Latina: Convergencias, disputas y alternativas en el siglo XXI”. Montevideo, Uruguay. 2018. Disponível

em: $\langle$ http://alasru2018.easyplanners.info/opc/?page=listado_completos\&numero_apellido=\&actividad=1 > Acesso em 30 mai.2020.

SILVA, Stéphanie Oliveira da. O futuro das indicações geográficas no estado do Pará. In: VII WORKSHOP CATARINENSE DE INDICAÇÃO GEOGRÁFICA. Corupá. 9, 10 e 11 de agosto de 2017. Anais do VII Workshop catarinense de indicação geográfica. Joinville, SC: Editora UNIVILLE, 2018. (p. 112-116). SOUSA, Fernando de. A Companhia Geral de Agricultura das Vinhas do Alto Douro : (1756-1978).

População e sociedade. Porto: CEPESE-Centro de Estudos da População, Economia e Sociedade, n. ${ }^{\circ} 10$, 2003, p. 9-58, 2003.

VALENTE, Andréa De Melo. Estudo da potencialidade de registro de indicação geográfica a produção de cacau no município de Medicilândia/PA. Dissertação (Mestrado) - Núcleo de Meio Ambiente, Universidade Federal do Pará, Programa de Pós-Graduação em Gestão de Recursos Naturais e Desenvolvimento Local na Amazônia, Belém, 2012. 120 f.

WANGHON, Moisés de Oliveira; COSTA, Cíntia Reis. Indicações geográficas como instrumento de proteção do patrimônio cultural imaterial. Revista da ABPI, n. 73, p. 3-8, 2004. 